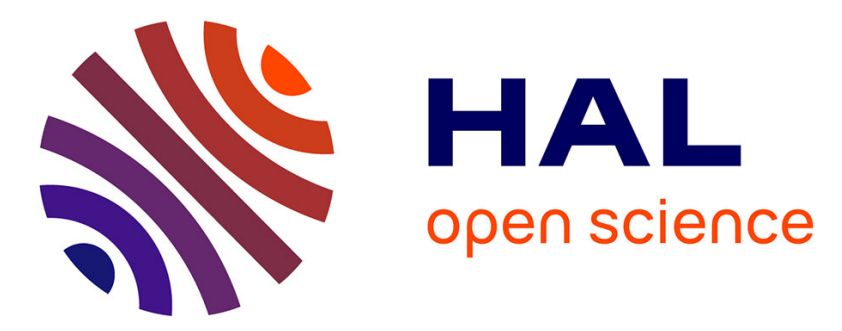

\title{
factor analysis of behavoiural symptoms in Huntington's Disease
}

\author{
Hugh Rickards, Jenny Keylock, Marleen van Walsem, Erik van Duijn, Sheila \\ Simpson, Ferdinando Squitieri, Bernhard Landwehrmeyer
}

\section{- To cite this version:}

Hugh Rickards, Jenny Keylock, Marleen van Walsem, Erik van Duijn, Sheila Simpson, et al.. factor analysis of behavoiural symptoms in Huntington's Disease. Journal of Neurology, Neurosurgery and Psychiatry, 2010, 82 (4), pp.411. 10.1136/jnnp.2009.181149 . hal-00576972

\section{HAL Id: hal-00576972 \\ https://hal.science/hal-00576972}

Submitted on 16 Mar 2011

HAL is a multi-disciplinary open access archive for the deposit and dissemination of scientific research documents, whether they are published or not. The documents may come from teaching and research institutions in France or abroad, or from public or private research centers.
L'archive ouverte pluridisciplinaire HAL, est destinée au dépôt et à la diffusion de documents scientifiques de niveau recherche, publiés ou non, émanant des établissements d'enseignement et de recherche français ou étrangers, des laboratoires publics ou privés. 
Factor Analysis of behavioural symptoms in Huntington's

disease.

Hugh Rickards MD*. Jenny Keylock MSc. Marleen van Walsem

MSc. Erik van Duijn MD. Sheila A Simpson MD. Ferdinando

Squitieri MD. Bernhard Landwehrmeyer MD. \& The European

Huntington's Disease Network.

Word count: 787.

* Corresponding author. Dr Hugh Rickards, Department of Neuropsychiatry, Barberry Building, 25 Vincent Drive, Edgbaston, Birmingham. B15 2FG. UK.

Telephone: 0044121301 2316. Fax: 00441213012291.

Email: hugh.rickards@bsmhft.nhs.uk

Search terms: Huntington's disease, factor analysis, behaviour, mental disorder.

Ms. Jenny Keylock, Birmingham and Solihull Mental Health Trust, Birmingham, UK. Ms. Marleen van Walsem, Rikshospitalet, Oslo, Norway. Dr Erik van Duijn, Leiden University Medical Centre, Leiden, Netherlands. Dr Sheila Simpson, Clinical Genetics Centre, Aberdeen, Scotland. Dr Ferdinando Squitieri, IRCCS-Neuromed, Pozilli, Italy. Prof. Bernhard Landwehermeyer, UIm University, Ulm, Ge rmany. 


\begin{abstract}
.
A principal components factor analysis was performed on behavioural data obtained from the European Huntington's Disease Network REGISTRY study. 1690 valid assessments using the United Huntington's Disease Rating Scale (UHDRS) Behavioural Rating Scale were included in the analysis. This large data set confirmed previous reports of distinct behavioural patterns within HD comprising of a depressive factor, a dysexecutive factor, an irritability factor and a psychosis factor.
\end{abstract}

\title{
Introduction
}

Huntington's disease (HD) is a progressive neuropsychiatric disorder consisting of motor, cognitive, behavioural, affective and perceptual changes. Psychiatric problems in HD are common and lead to significant impairment in the Quality of Life of people with $\mathrm{HD}^{1,2}$. The Behaviour section of the Unified Huntington's Disease Rating Scale (UHDRS) was designed to record a range of psychiatric phenomena in people with $\mathrm{HD}^{3}$. There are few studies analysing the relationship between different psychiatric phenomena in HD. Marder et al ${ }^{4}$ performed a factor analysis on 960 UHDRS assessments as part of the Huntington's Study Group (HSG) project. They isolated 15 factors, including "depression/anxiety", "suicidal thoughts", "aggressivity" and "obsessive/compulsive". There were a number of smaller factors including hallucinations in different modalities, something not routinely enquired about in current UHDRS assessment. Craufurd et al $\left.\right|^{5}$ used factor analysis to examine data on 78 patients with HD who had undergone the Problem Behaviours Assessment in HD (PBA-HD). Principal components factor analysis revealed 3 clusters of symptoms, reflecting apathy, depression and irritability. The apathy factor was closely related to the duration of illness, being a stronger feature later in the illness. A further paper by Kingma et $\mathrm{al}^{6}$ using the PBA on 152 HD mutation carriers also showed a 3 factor solution; apathy, depression and irritability. 
The European Huntington's Disease Network (EHDN) REGISTRY study (www.euro-

hd.net/html/registry) has provided a unique opportunity to re-examine psychiatric symptoms in the setting of HD. This study has recruited around 4000 people with HD and participants are followed up at yearly intervals.

The aim of our study was to perform a factor analysis on all the completed UHDRS behavioural assessments performed across Europe since the inception of the REGISTRY study. The total number of fully completed assessments at the time of writing was 1690 . Elucidation of specific behavioural or psychiatric factors may lead to the identification of specific phenotypes within HD, which in turn could lead to greater insight into aetiology and aid with treatment.

\section{Method.}

Data were made available from the EHDN REGISTRY database following approval from the Scientific and Bioethical Advisory committee and the Executive committee of the EHDN. UHDRS behaviour scores were obtained for 1803 assessments on individual participants. The UHDRS behaviour section is made up of 11 individual items, each scored on the dimensions of frequency and severity. The frequency (score 0-4 points) and severity (score 0-4 points) of each item were multiplied to give a single score for each item. The item scores are then added together to give the total behaviour score.

Principal components analysis was employed, with the "frequency multiplied by severity" score for each item used as a factor. Data on all the factors were analysed using SPSS v.16. A Varimax rotation was utilised with Kaiser Normalisation. Due to missing data, 113 cases were excluded to give a final $\mathrm{N}$ of 1690 . Full ethical approval was obtained for this study. 
Results.

\begin{tabular}{|c|c|c|c|c|}
\hline & 1 & 2 & 3 & 4 \\
\hline $\begin{array}{l}\text { Depressed } \\
\text { mood }\end{array}$ & .811 & .140 & .122 & \\
\hline $\begin{array}{l}\text { Low self- } \\
\text { esteem }\end{array}$ & .792 & & .117 & \\
\hline Suicidal & .662 & & .124 & .187 \\
\hline Anxiety & .649 & .276 & .113 & \\
\hline Compulsions & & .848 & & \\
\hline Perseveration & .178 & .763 & .203 & .124 \\
\hline Apathy & .288 & .418 & .179 & \\
\hline Aggression & .141 & & .887 & \\
\hline Irritability & .229 & .241 & .807 & \\
\hline Hallucinations & & & & .852 \\
\hline Delusions & & .257 & .106 & .760 \\
\hline
\end{tabular}

Table 1. Factor analysis of behavioural symptoms in Huntington'sDisease. $\mathrm{N}=1690$

Extraction method: Principal Components Analysis

Rotation method: Varimax with Kaiser normalisation

Data included in bold if factor $>0.4$

As seen in Table 1, four factors achieved a loading of over 0.4 . These factors accounted with $63.8 \%$ of variance in the total score. The four factors were;

1. Depression (depressed mood, low self-esteem, suicidal ideation, anxiety) 
2. Drive/executive function ( perseveration, compulsion, apathy)

3. Irritability/aggression

4. Psychosis (delusions and hallucinations).

There was a good delineation between factors with each item clearly loading to one of the four factors. All factors achieving the threshold of 0.4 were at least 0.6 . Eigenvalues, after rotation, were as follows; depression (2.340), drive/executive function (1.714), aggression/irritability (1.580), psychosis (1.385).

\section{Discussion.}

This factor analysis builds on the findings of Craufurd et $\mathrm{al}^{5}$ and Kingma et $\mathrm{al}^{6}$ who both used the PBA and Marder et $\mathrm{al}^{4}$ who used an old version of the UHDRS Behaviour assessment. All the studies have shown distinct factors for depression, executive functions and irritability. Both studies using the UHDRS behaviour section had separate factors for psychosis.

These data further support the existence of specific clusters of psychiatric symptoms in HD, which may be related discretely to affect, executive function, aggression/irritability and perception. More research is needed to assess the validity of these categories, as well as their stability over time, including in the pre-manifest period. Further work is needed to develop valid rating scales that measure change in these factors as a result of treatment.

\section{Conclusion.}

Distinct clusters of behavioural symptoms are emerging in HD. These relate in general to depression, executive function, irritability and psychosis. Further studies should aim to tie in these factors with specific endophenotypes in order to establish clear clinico-pathological correlation. 


\section{Acknowledgements.}

The authors would like to acknowledge the behavioural phenotype working group of the EHDN (www.euro-hd.net/html/network/groups/behavioural) and CHDI Foundation, Inc. The list of contributors to the data set is given below (Appendix 1).

\section{Competing Interests}

This study received no sponsorship and was led by the investigators.

Dr Rickards has sat on an advisory board for MEDA pharmaceuticals. He has been paid honoraria for work for Cambridge Laboratories.

Dr. Simpson received an honorarium from Cambridge Pharmaceuticals for consultancy.

Jenny Keylock reports no disclosures

Marleen van Walsem reports no disclosures

Dr van Duijn reports no disclosures

Dr. Squitieri reports no disclosures

Prof. Landwehrmeyer reports no disclosures

Licence for Publication:

The Corresponding Author has the right to grant on behalf of all authors and does grant on behalf of all authors, an exclusive licence (or non exclusive for government employees) on a worldwide basis to the BMJ Publishing Group Ltd to permit this article (if accepted) to be published in PMJ and any other BMJPGL products and sublicences such use and exploit all 
subsidiary rights, as set out in our licence.

(http://group.bmj.com/products/journals/instructions-

for-authors/licence-forms)

\section{Authors' Appointments}

\section{*Dr Hugh Rickards}

Consultant in Neuropsychiatry. Honorary Senior Clinical Lecturer in Psychiatry

Department of Neuropsychiatry

Birmingham and Solihull Mental Health Foundation Trust

Barberry Building, 25 Vincent Drive, Edgbaston.

Birmingham B15 2FG. United Kingdom.

\section{Ms. Marleen R van Walsem.}

EHDN Coordinator for Nordic Countries / Neuropsychologist

Rikshospitalet

Centre for Rare Disorders

Forskningsveien 3B

0027 Oslo

Norway 


\section{Ms Jenny Keylock}

Research Psychologist

Department of Neuropsychiatry

Birmingham and Solihull Mental Health Foundation Trust

Barberry Building, 25 Vincent Drive, Edgbaston.

Birmingham B15 2FG. United Kingdom

\section{Dr Erik van Duijn}

Psychiatrist

Leiden University Medical Center, Department of Psychiatry

PO Box 9600

2300 RC Leiden

The Netherlands

\section{Dr. Ferdinando Squitieri}

Head of Neurogenetics Unit

IRCCS Neuromed - Centre for Rare Diseases

Localita' Camerelle - 86077

Pozzilli (IS) - Italy

Tel.: +390865915238

Fax: +390865 927575 


\section{Dr Sheila A. Simpson FRCP (Edin)}

Consultant Clinical Geneticist/ Honorary Senior Lecturer

First Floor Argyll House

Foresterhill

Cornhill Road

ABERDEEN. SCOTLAND

AB25 2ZR

\section{Prof. Bernhard Landwehrmeyer}

Professor of Neurology

Oberer Eselsberg 45/1

89081 Ulm

Deutschland

* Address for correspondence.

Bibliography

1. Paulsen JS, Ready RE, Hamilton JM, Mega MS, Cummings JL (2001) Neuropsychiatric aspects of Huntington's disease. Journal of Neurology, Neurosurgery and Psychiatry. 71(3): 310-314.

2. Ho, A.K., Robbins A.O.G., Walters S.J., Kaptoge S., Sahakian, B.J. and Barker R.A. (2004). Healthrelated quality of life in Huntington's disease: A comparison of two generic instruments, SF-36 and SIP. Movement Disorders. 19(11): 1341-1348.

3. Huntington Study Group (1996). Unified Huntington's Disease Rating Scale: reliability and consistency. Movement Disorders. 11: 136-142. 
4. Marder K, Zhao H, Myers RH et al (2000) Rate of functional decline in Huntington's disease. Neurology. 54:452-458.

5. Craufurd D, Thompson J \& Snowden JS (2001) Behavioural changes in Huntington's disease. Neuropsychiatry, Neuropsychology and Behavioural Neurology. 14(4): 219-226.

6. Kingma EM, van Duijn E, Timman R et al (2008) Behavioural problems in Huntington's disease using the Problem Behaviours Assessment. General Hospital Psychiatry. 30: 155-161

Appendix 1. Names of all clinicians contributing UHDRS behaviour ratings to the EHDNREGISTRY database. 